\title{
ATTENUATION AND PENETRATION OF VISIBLE 632.8nm AND IN VISIBLE INFRA-RED 904nm LIGHT IN SOFT TISSUES
}

\author{
Chukuka S. E nwemeka, Ph.D ., FA CSM \\ D epartment of Physical Therapy \& Rehabilitation Sciences, U niversity of Kansas M edical C enter, Kansas \\ City, KS, and D epartment of V eterans A ffairs M edical C enter, Kansas City, M 0, U.S.A .
}

We studied the depth of penetration and the magnitude of attenuation of $632.8 \mathrm{~nm}$ and 904nm light in skin, muscle, tendon, and cartilagenous tissues of live anaesthetized rabbits. Tissue specimens were dissected, prepared, and their thicknesses measured. Then, each wavelength of light was applied. Simultaneously, a power meter was used to detect and measure the amount of light transmitted through each tissue. All measurements were made in the dark to minimize interference from extraneous light sources. To determine the influence of pulse rate on beam attenuation, the $632.8 \mathrm{~nm}$ light was used at two predetermined settings of the machine; continuous mode and 100 pulses per second (pps), at an on:off ratio of 1:1. Similarly, the $904 \mathrm{~nm}$ infra-red light was applied using two predetermined machine settings: 292 pps and 2,336 pps. Multiple regression analysis of the data obtained showed significant positive correlations between tissue thickness and light attenuation $(p<.001)$. Student's t-tests revealed that beam attenuation was significantly affected by wavelength. Collectively, our findings warrant the conclusions that (1) The calf muscles of the $\mathrm{New}$ Zealand white rabbit attenuates light in direct proportion to its thickness. In this tissue, light attenuation is not significantly affected by the overlying skin, a finding which may be applicable to other muscles. (2) The depth of penetration of a $632.8 \mathrm{~nm}$ and $904 \mathrm{~nm}$ light is not related to the average power of the light source. The depth of penetration is the same notwithstanding the average power of the light source. (3) Compared to the 904nm wavelength, $632.8 \mathrm{~nm}$ light is attenuated more by muscle tissue, suggesting that is is absorbed more readily than the $904 \mathrm{~nm}$ wavelength or conversely that the $904 \mathrm{~nm}$ wavelength penetrates more. Thus, wavelength plays a critical role in the depth of penetration of light.

key words: L aser Therapy, L ight A ttenuation, L ight A sorption.

\section{Introduction}

As early as 1968, Mester and his associates [1-3] demonstrated that, at low power, red light promotes tissue repair. In the intervening period since then, the therapeutic value of phototherapy has been argued and debated by many, with several studies supporting the original hypothesis that they promote tissue repair processes in experimental animals [4-32] and human wounds and ulcers [8, 33-38], and others [39-46], suggesting the contrary.

A review of well controlled in vitro and in vivo laboratory experiments reveals a trend that suggests that low intensity lasers enhance wound healing by promoting cell proliferation [8, 28-30, 41-44], accelerating the formation of granulation tissue, promoting collagen synthesis [3-13, 4761], fostering the formation of type I and type III procollagen specific pools of mRNA [62], increasing ATP synthesis within the mitochondria, activating lymphocytes, and increasing their abilities to bind pathogens [10, 52]. The trend is not as clear when clinical reports on tissue repair are examined. Rather, sufficient differences of opin- ion seem evident between studies showing beneficial effects and those reporting no effects whatsoever [10, 3346].

Given the multitude of treatment parameters used in these studies, i.e., wavelength, pulsed versus continuous wave light, energy fluence, power density, exposure time, frequency and total duration of treatment, it is not surprising that results differ from one study to the next. A good understanding of the nature of light-tissue interaction could simplify and ease the choice of treatment parameters. In this regard, Welch et al [63], have provided a mathematical model that offers a fairly simple method of determining light distribution in tissues. However, their model seems significantly limited, as it applies to $\mathrm{CO}_{2}$, Excimer and Er:YAG lasers, situations involving high scattering of light and tissue depths that are less than $40 \mathrm{~mm}$. Beer's Law which indicates that the incident light is exponentially attenuated as it passes through tissue, and Kubelka-Munk theory, a two-flux model used for uniformly diffused incident light, can be used to compute quantitative laser 
absorption in blood and skin. However, neither Beer's Law nor Kubelka-Munk theory accounts for the scattering of light in tissues. Other models, e.g., the "Diffusion Approximation Model", assumes that light is scattered almost uniformly after encountering numerous scattering events, but this is not always the case.

We have used the transected rabbit Achilles tendon and rat skin lesions as models for determining the biomechanical, ultrastructural and biochemical effects of light on tissue repair. Because none of the models described above can be used to account for light-tissue interaction in our experimental model, we determined the depth of penetration and the extent of attenuation of light by the variety of tissues associated with our tendon repair model. O ur specific aims were: (1) to determine the depth of penetration of 632.8nm (Ne:He) and 904nm (Ga:As) lasers through specific tissue types and thicknesses, (2) to compare the attenuating effects of skin, muscle, tendon, and cartilage on low energy light, (3) to determine the effects of tissue type and thickness on beam attenuation. Attenuation is operationally defined as the amount of light that is prevented from passing through tissue, primarily due to absorption, reflection and refraction of the light beam.

\section{Methods}

A nimals

Four 4-6 month-old New Zealand white rabbits, housed one per standard $30.5 \times 71$ x $51 \mathrm{~cm}$ rabbit cage in an environment maintained at $22+1^{\circ} \mathrm{C}$ and fed rabbit chow and water ad libitum, were used for this study.

A nimal Preparation

Each rabbit was weighed, then anesthetized with a mixture of $180 \mathrm{mg}$ of xylazene, $900 \mathrm{mg}$ of ketamine and $30 \mathrm{mg}$ of acepromazine by intramuscular injection into the quadriceps muscle of $1 \mathrm{m1} / 1.5 \mathrm{~kg}$ body weight. Following satisfactory anesthesia, the animal was prepared for surgery and a longitudinal incision was made, approximately $1 \mathrm{~cm}$ lateral to the visible outline of the calcaneal tendon. Blunt dissection was used to separate the tendon and the triceps surae muscle group from adjoining tissue. Thereafter, the tendon was severed sharply and transversely just proximal to its calcaneal attachment, but left connected to its muscle.

L ight M easurement.

A He:Ne laser unit (Dynatronics Inc., Salt Lake City, UT) of $632.8 \mathrm{~nm}$ wavelength and $11 \mathrm{~mW}$ maximum power, and a $\mathrm{G}$ a:As laser unit (Respond Systems Inc., Madison, CT) of $940 \mathrm{~nm}$ wavelength and $7 \mathrm{~mW}$ maximum power, were used throughout the study. A customized power meter
(United D etector Technology, model S351L, Hawthorne, CA), calibrated to measure light intensity (power) within the range of $450 \mathrm{~nm}$ to $1000 \mathrm{~nm}$, was used to measure the amount of light passing through each selected tissue. The photoreceptor of the power meter was secured in a stand as shown in figure 1. The laser applicator was then placed perpendicular to the photoreceptor of the power meter with the target tissue sandwiched between the photoreceptor and the applicator (Figure 2). With the target tissue in place, the power of each laser unit was varied by altering the pulse rate. Pulse rates of 2,336 PPS and 292 PPS were used for the $904 \mathrm{~nm}$ light, yielding average power outputs of $6.5 \mathrm{~mW}$ and $0.8 \mathrm{~mW}$ respectively. Zero PPS (i.e. continuous beam) and 100 PPS were used for the He:Ne laser. The target tissues irradiated included the ear, the calcaneal tendon, the triceps surae muscle group and the skin overlying the calf muscles.

$\mathrm{D}$ ata A nalysis.

Multiple regression analysis was used to determine the effect of tissue thickness on the amount of light attenuated by the tissue under the experimental conditions. Student's t-test was then used to determine the effect of these variables on light attenuation.

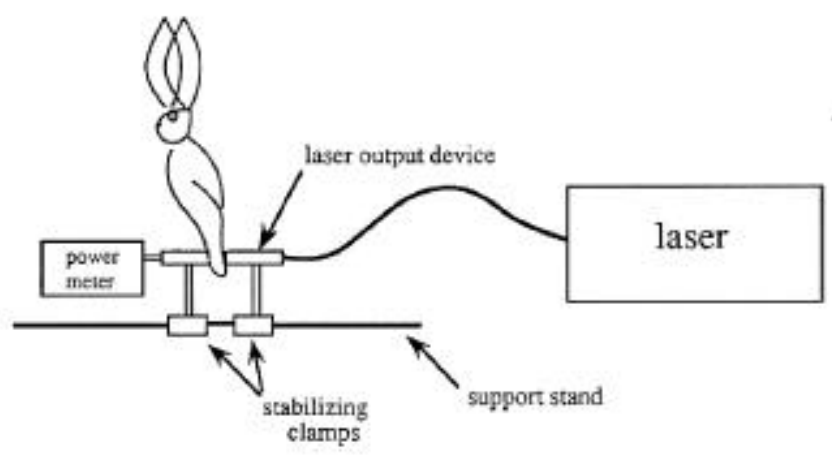

Figure 1. Illustration of our ex perimental setup.

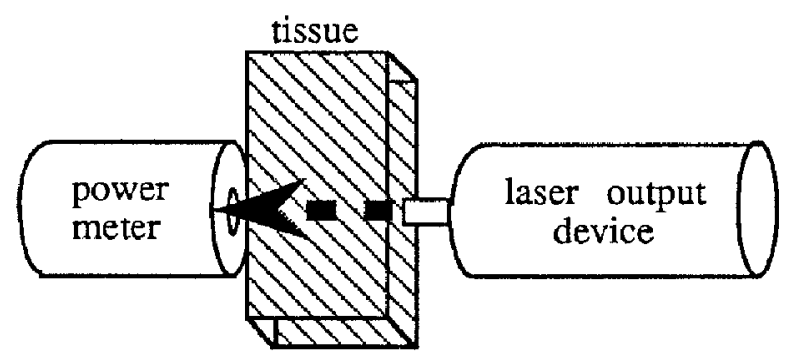

Figure 2. Illustration showing a dose up view of laser application, tissue specimen, and beam measurement with the power meter.

\section{Results}

In each of the tissues tested, there was a significant posi- 
tive correlation between tissue thickness and beam attenuation (Tables $1 \& 2$ ). At both wavelengths beam attenuation per millimeter of tissue was greater for muscle and cartilage compared to all other tissues, i.e., skin and muscle combined, tendon, and skin and tendon combined (Figs. 3 $\&$ 4), suggesting that these wavelengths, i.e., $632.8 \mathrm{~nm}$ and $904 \mathrm{~nm}$ are absorbed more by muscle and cartilage than any of the other tissues tested. Furthermore, attenuation per millimeter of tissue was significantly greater for cartilage(the ear) than tendon, two similarly dense connective tissues; (cartilage $=2.44$ and $2.27 \mathrm{~mW} / \mathrm{mm}$ and tendon $=$ 1.22 and $1.48 \mathrm{~mW} / \mathrm{mm}$, for $904 \mathrm{~nm}$ and $632.8 \mathrm{~nm}$ wavelengths respectively). The low amount of beam attenuation by tendon relative to its analogue, cartilage, and the similarity in the magnitude of beam attenuation of both wavelengths by two morphologically dissimilar tissues, muscle and cartilage, suggest that tissue density is not a primary determinant of beam attenuation.

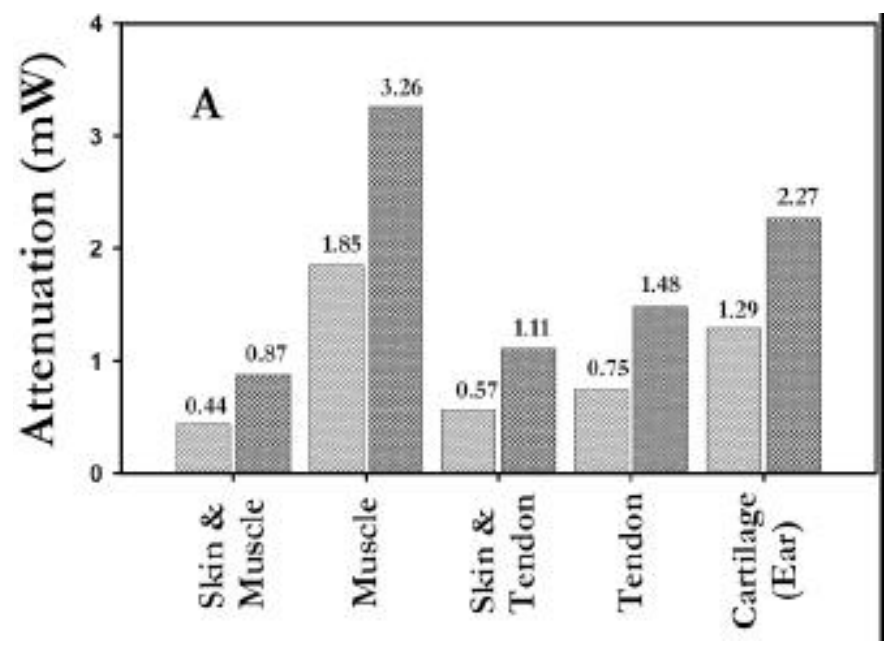

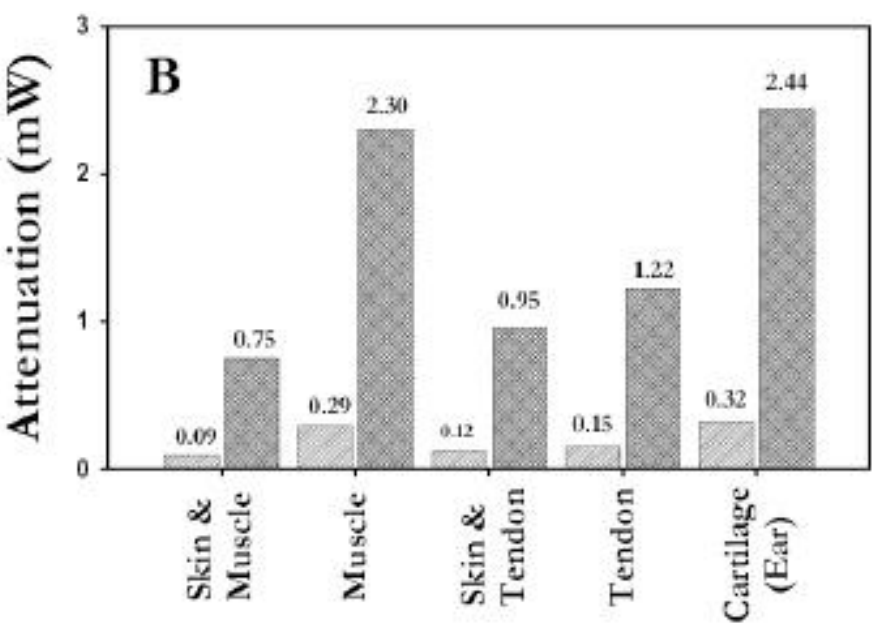

Fig 3: A ttenuation of light by various tissues, (A) A ttenuation of 632.8 $\mathrm{nm}$ red light per millimeter of tissue. L ighter bar=pulsed beam; D ark bar= continuous beam. (B) A ttenuation of invisible infra-red $904 \mathrm{~nm}$ light per millimeter of tissue (L ight bar=292 pps; D ark bar=2,336 pps).

Furthermore, attenuation of the invisible infra-red $904 \mathrm{~nm}$ wavelength was significantly higher in all the tissues tested and in all modes of application, i.e., pulsed or continuous, when compared with the $632.8 \mathrm{~nm}$ beam, except in muscle tissue where the $632.8 \mathrm{~nm}$ wavelength was more attenuated (Fig. 4; $p<.05$ in each case). Although the absolute amount of beam attenuation was higher when both wavelengths were applied at each machine's optimal intensity compared to their respective pulsed intensities, as shown in figure 3B, the relative amount of beam attenuation was essentially the same for each tissue in both modes of application. Thus, the attenuation of either wavelength of light was not affected by the two modes of application, pulsed or continuous.
Table 1: 632.8nm Wavelength

\begin{tabular}{|l|c|c|c|l|}
\hline Tissue & $\mathbf{r}$ & $\mathbf{R}^{\mathbf{2}}$ & \multicolumn{1}{|c|}{$\mathbf{p}$} & $\mathbf{~ N}$ \\
\hline Muscle & .591 & .350 & $<.0001$ & 36 \\
\hline $\begin{array}{l}\text { Skin \& } \\
\text { Muscle }\end{array}$ & .887 & .786 & $<.0001$ & 9 \\
\hline Muscle & .725 & .526 & $<.0001$ & 36 \\
\hline Tendon & .690 & .476 & $<.0001$ & 9 \\
\hline
\end{tabular}

Table 1. Correlation of $632.8 \mathrm{~nm}$ beam attenuation and tissue thickness for the various tissues tested. $(r=$ Pearson's correlation coefficient; $\mathrm{R}^{2}=$ coefficient of determination, i.e., the amount of variance in attenuation predicted by knowing the average power of the light source, and $\mathrm{N}=$ number of specimens tested).
Table 2: 904nm Wavelength

\begin{tabular}{|l|c|c|c|l|}
\hline Tissue & $\mathbf{r}$ & $\mathbf{R}^{\mathbf{2}}$ & \multicolumn{1}{|c|}{$\mathbf{p}$} & $\mathbf{N}$ \\
\hline Muscle & .801 & .641 & $<.0001$ & 36 \\
\hline $\begin{array}{l}\text { Skin \& } \\
\text { Muscle }\end{array}$ & .904 & .818 & $<.0001$ & 9 \\
\hline Muscle & .876 & .767 & $<.0001$ & 24 \\
\hline Tendon & .976 & .953 & $<.0001$ & 9 \\
\hline
\end{tabular}

Table 2. Correlation of $904 \mathrm{~nm}$ beam attenuation and tissue thickness for the various tissues tested. ( $r=$ Pearson's correlation coefficient; $\mathrm{R}^{2}=$ coefficient of determination, i.e., the amount of variance in attenuation predicted by knowing the average power of the light source, and $\mathrm{N}=$ number of specimens tested). 
The gastrocsoleus muscle was the only tissue that we were able to vary the thickness appreciably enough to derive pedictive equations for beam attenuation at various thicknesses. For this tissue, it was possible to predict the attenuation of $632.8 \mathrm{~nm}$ and $904 \mathrm{~nm}$ light at increasing thicknesses as indicated in the following equations:

$$
\mathrm{y}=4.38 \times 10^{-2} \mathrm{x}+6.59 \text { (for } 904 \mathrm{~nm} \text { light pulsed at 2,336 pps) }
$$

$\mathrm{y}=6.17 \times 10^{-3} \mathrm{x}+8.23 \times 10^{-1}$ (for $904 \mathrm{~nm}$ pulsed at $292 \mathrm{pps}$ )

$\mathrm{y}=3.17 \times 10^{-2} \mathrm{x}+7.67$ (for $632.8 \mathrm{~nm}$ continuous wave light)

$\mathrm{y}=2.0610^{-2} \mathrm{x}+3.91$ (for $632.8 \mathrm{~nm}$ light pulsed at $100 \mathrm{pps}$ )

(W here $\mathrm{y}=$ the amount of attenuation and $\mathrm{x}=$ the average power of the laser deviœ).


Fig. 4: A ttenuation of light by various tissues as a percentage of the average power of the laser source. (A) Percent attenuation of $632.8 \mathrm{~nm}$ light; (L ight bar= pulsed; dark bar= ontinuous). (B) Percent attenuation of $904 \mathrm{~nm}$ light. (L ight bar= 292 ppp; dark bar=2,336 pps)

\section{Discussion}

Attenuation of light can be accounted for by three major factors, light absorption, light reflection, and light refraction. In soft tissue absorption accounts for a significant amount of beam attenuation, except in situations involving an unusually high amount of beam reflection or when light is applied to the tissue in the non-contact mode. O ur findings indicate that the $632.8 \mathrm{~nm}$ and the $904 \mathrm{~nm}$ wavelengths of light are capable of penetrating skin, muscle, tendon, cartilage, and also a combination of skin and muscle, and skin and tendon. And that each tissue type attenuates both wavelengths of light. Given the optical characteristics of these tissues, and the fact that the applicator of each light source was used in direct contact with each tissue, it seems safe to assume that these two wavelengths of light are significantly absorbed by all the tissues tested, in particular, muscle and cartilage, which attenuated more than 35\% and $26 \%$ of either wavelength of light per millimeter of tissue respectively.

Attenuation of light per millimeter of tissue differed significantly from tissue to tissue. Cartilage and muscle attenuated light more than any of the other tissues tested. And although cartilage and tendons are more akin to one another, both being dense connective tissues, light attenuation by both tissues was significantly different. In contrast, muscle and cartilage, two morphologically dissimilar tissues, attenuated $904 \mathrm{~nm}$ light to the same extent, buttressing the notion that factors other than tissue thickness account for light attenuation by soft tissues.

Compared to the infra-red $904 \mathrm{~nm}$ wavelength, red 632.8 $\mathrm{nm}$ light was attenuated more by muscle than any of the other tissues. Thus, the data clearly indicate that $904 \mathrm{~nm}$ light penetrates muscle tissue more than $632.8 \mathrm{~nm}$ light. This finding is consistent with that of Al-Watban and Andres (reported in this issue of the journal). However, whether or not the observed differences in absorption and penetration have any effects on tissue healing is beyond the scope of this study.

Skin was found to have no significant effect on light attenuation through muscle (Figure 3). The ability of low intensity light to penetrate skin with minimal beam scattering (reflection and refraction) should permit the use of therapeutic light to effectively treat sub-dermal lesions.

Attenuation, in the context of this paper, represents the amount by which light energy is diminished as it passes through the tissue. Thus, it represents the amount of light absorbed, reflected, or refracted such that the beam could not continue in the direction of application. Given this definition, it will be erroneous to assume that the attenuation figures obtained in this study represents the amount of light absorbed by the tissues. Actual determination of beam scattering and measurement of the exact amount of light absorbed by the tissue are subjects of future studies. However, the relative amounts of light attenuated by the various tissues tested could reflect the relative amounts of light absorbed by the tissues. 


\section{Conclusion}

Our findings mandate the following conclusions: (1) The calf muscles of the New Zealand white rabbit attenuates light in direct proportion to its thickness. In this tissue, light attenuation is not significantly affected by the overlying skin, a finding which may be applicable to other muscles. (2) The depth of penetration of a $632.8 \mathrm{~nm}$ and $904 \mathrm{~nm}$ light is not related to the average power of the light source. For each of the wavelengths tested, the depth of penetration is the same notwithstanding the average power of the light source. (3) Compared to the $904 \mathrm{~nm}$ wavelength, $632.8 \mathrm{~nm}$ light is attenuated more by muscle tissue, suggesting that is is absorbed more readily than the $904 \mathrm{~nm}$ wavelength or conversely that the $904 \mathrm{~nm}$ wavelength penetrates more. Thus, wavelength plays a critical role in the depth of penetration of light.

A ddress correspondence to:

Chukuka S. Enwemeka, Ph.D., FACSM

Professor \& Chairman

D epartment of Physical Therapy \& Rehabilitation Sciences University of Kansas Medical Center

Kansas City, KS 66160-7601

Phone: +1-913-588-6799

Fax: $\quad+1-913-588-4568$

Email: Enwemeka@kumc.edu

\section{REFERENCES}

1. Mester E, Ludany M, Sellyei M: The stimulating effect of low power laser ray on biological systems. Laser Review (London) 1:3, 1968.

2. Mester E, Spiry T, Szende B, Tota JG. Effect of laser rays on wound healing. Am J Surg, 122:532-535,1971.

3. Mester E, Jaszsagi-Nagi E: The effects of laser irradiation on wound healing and collagen synthesis. Studia Biophysica, 35: 227-230, 1973.

4. Enwemeka CS. Laser biostimulation of healing wounds: specific effects and mechanism on action. J. Orthop Sports Phys Ther. 9:333-338, 1988.

5. Enwemeka CS.: Laser Photostimulation. Clinical Management, 10:24 29, 1990.

6. Reddy GK, Stehno-Bittel L, Enwemeka CS. Laser photostimulation of collagen production in healing rabbit Achilles tendons. Lasers Surg Med: 22:281-287, 1998.

7. Enwemeka CS, Cohen E, D uswalt EP, Weber D M: The Biomechanical effects of Ga-As Laser photostimulation on tendon healing. Laser Therapy 6:181-188, 1995.

8. Enwemeka CS: Ultrastructural morphometry of Membrane-bound intracytoplasmic collagen fibrils in tendon fibroblasts exposed to He:Ne laser beam. Tissue \& Cell 24: 511-523, 1992

9. Enwemeka CS: Laser photostimulation in the United States - A tale of clinical tests, experimental trials, tran- sient triumphs, and intermittent tribulations of potential clinical armamentarium. in Ohshiro, T. and Calderhead, R.G., eds.), Progress in Laser Therapy Vol. Toronto: John Wiley: 102-111, 1991.

10. Mester E, Mester AF, Mester A. The biomedical effects of laser application. Lasers Surg Med. 5:31-39, 1985.

11. Conlan MJ, Rapley JW, Cobb CM. Biostimulation of wound healing by low-energy laser irradiation. A review. J Clin Periodont 23:492-496, 1996.

12. Yu W, Naim JO, Lanzafame RJ. Effects of photostimulation on wound healing in diabetic mice. Lasers Surg Med. 20: 56-63, 1997.

13. Crespi R, Covani U, Margarone JE, Andreana S. Periodontal tissue regeneration in beagle dogs after laser therapy. Lasers Surg Med: 21: 395-402, 1997.

14. Sugrue ME, Carolan J, Leen EJ, Feeley TM, Moore DJ, Shanik GD. The use of infrared laser therapy in the treatment of venous ulceration. Annals Vasc Surg, 4: 179-181, 1990.

15. Rezvani M, Robbins MEC, Hopewell JW, Whitehouse EM. Modification of late dermal necrosis in the pig by treatment with multi-wavelength light. Brit J Radiology: 66: 145-149, 1993.

16. Braverman $B$, McCarthy RJ, Ivankovich AD, Forde DE, Overfield M, Bapna MS. Effect of helium-neon and infrared laser irradiation on wound healing in rabbits. Lasers Surg Med: 9: 50-58, 1989.

17. Longo L, Evangelista S, Tinacci G, Sesti AG. Effect of diodes-laser silver arsenide-aluminum (Gs-Al-As) 904 $\mathrm{nm}$ on healing of experimental wounds. Lasers Surg Med: 7: 444-447, 1987.

18. Al-Watban FAH, Z hang XY. Stimulative and inhibitory effects of low incident levels of argon laser energy on wound healing. Laser Ther: 7: 11-18, 1995.

19. Lee P, Kim K, Kim K. Effects of low incident energy levels of infrared laser irradiation on healing of infected open skin wounds in rats. Laser Ther: 5: 59-64, 1993.

20. Ghamsari SM, Taguchi K, Abe N, Acorda JA, Sato M, Yamada H. Evaluation of low level laser therapy on primary healing of experimentally induced full thickness teat wounds in dairy cattle. Vet Surg: 26: 114-120, 1997.

21. Ghamsari SM, Yamada H, Acorda JA, Unno N. Evaluation of low level laser therapy on open wound healing of the teat in dairy cattle. Laser Ther: 6: 113118, 1994.

22. Al-Watban FAH, Zhang XY. Comparison of the effects of laser therapy on wound healing using different laser wavelengths. Laser Ther: 8: 127-135, 1996.

23. Al-Watban FAH, Zhang XY. Comparison of wound healing process using argon and krypton lasers. J Clin 
Laser Med Surg: 15: 209-215, 1997.

24. Hunter J, Leonard L, Wilson R, Snider G, Dixon J. Effects of low energy laser on wound healing in a porcine model. Lasers Surg Med: 1984; 3: 285-290.

25. Sasaki K, O hshiro T. Assessment in the rat model of the effects of $830 \mathrm{~nm}$ diode laser irradiation in a diachronic wound healing study. Laser Ther: 9: 25-32, 1997.

26. Kana JS, Hutschenreiter G, Haina D, Waidelich W. Effect of low-power density laser radiation on healing of open skin wounds in rats. Arch Surg: 116: 293-296, 1981.

27. Halevy S, Lubart R, Reuvani H, Grossman N. Infrared $(780 \mathrm{~nm})$ low level laser therapy for wound healing: in vivo and in vitro studies. Laser Ther: 9: 159-164, 1997.

28. Braverman $B$, McCarthy RJ, Ivankovich $A D$, forde $D E$, O verfield M, and Bapna MS. Effect of helium neon and infared laser irradiation of wound healing in rabbits. Lasers in Surgery and Medicine, 9: 50 58, 1989.

29. Hunter J, Leonard L, Wilson R, Snider G. and Dixon J. Effects of low energy laser on wound healing in a porcine model. Lasers in Surgery and Medicine, 3: 285290, 1984.

30. Houghton PE, Keefer KA, and Krummel TM. Transforming G rowth Factor Beta (TGF1) plays a role in conversion of 'scarless' fetal wound healing to healing with scar formation. Wound Repair and Regeneration, 3: 54-61, 1994.

31. Thawer HL, and Houghton PE: Effects of laser irradiation on fetal limb development in vitro. Lasers in Surgery and Medicine, 24: 285-295, 1999.

32. Houghton PE, Keefer KA, and Krummel TM: A simple method for the assessment of the relative amount of scar formation in wounded fetal mouse limbs. Wound Repair and Regeneration, 4:489-495, 1996.

33. Mester E. Laser application in promoting of wound haling in Koebner, N., ed., Laser in Medicine Vol. Toronto: John Wiley, 83-85, 1980.

34. Gamaleya N. Laser biomedical research in USSR in Wolbarsht, M., ed., Laser applications in medicine and biology Vol. London: Plenum Press, 1-175, 1977.

35. Schindl A, Schindl M, Schindl L. Successful treatment of a persistent radiation ulcer by low power laser therapy. J Am Acad D ermatol, 37:646-648, 1997.

36. Schindl A, Schindl M, Schind L. Phototherapy with low intensity laser irradiation for a chronic radiation ulcer in a patient with lupus erythematosus and diabetes mellitus [letter]. Br J D ermatol, 137: 840-841, 1997.

37. Schindl A, Schindl M, Schon H, Knobler R, Havelec L, Schindl L. Low-intensity laser irradiation improves skin circulation in patients with diabetic microangiopathy. Diabetes Care, 21: 580-584, 1998.

38. Schindl A, Schindl M, Pernerstorfer-Schon H, Schindl L.
Low-intensity laser therapy: a review. J Investig D erm 48:312-326, 2000.

39. Basford JR, Hallman HO, Sheffield CG, Mackey GL. Comparison of cold-quartz ultraviolet, low-energy laser, and occlusion in wound healing in a swine model. Arch Phys Med Rehabil: 67: 151-154, 1986.

40. Lundeberg T, Malm M. Low-power HeNe laser treatment of venous leg ulcers. Annals Plastic Surg: 27: 537-539, 1991.

41. Nussbaum EL, Biemann I, Mustard B. Comparison of ultrasound/ ultraviolet-C and laser for treatment of pressure ulcers in patients with spinal cord injury. Phys Ther: 74: 812-823, 1994.

42. Basford JR. Laser therapy: scientific basis and clinical role. Lasers O rtho Surg. 16(5):541-547, 1993.

43. McMeeken J, and Stillman B: Perceptions of the efficacy of laser therapy. Australian Physiotherapy, 39:101 106, 1993.

44. Basford JR: Low energy laser therapy: controversies and new research findings. Lasers in Surgery and Medicine, 9:1 5, 1989.

45. Bouma MG, Buurman WA, and van den Wildenberg FAJM: Low energy laser irradiation fails to modulate the inflammatory function of human monocytes and endothelial cells. Lasers in Surgery and Medicine, 19:207 215, 1996.

46. Allendorf JDF, Bessler M, Huang J, Kayton ML, Laird D, Nowygrod R, and Treat MR: Helium neon laser irradiation at fluences of 1,2 and $4 \mathrm{~J} / \mathrm{cm} 2$ failed to accelerated wound healing as assessed by both wound contracture rate and tensile strength. Lasers in Surgery and Medicine, 20:340 345, 1997.

47. El Sayed SO, Dyson M. Effect of laser pulse repetition rate and pulse duration on mast cell number and degranulation. Lasers Surg Med, 19: 433-437, 1996.

48. El Sayed SO, Dyson M. Comparison of the effect of multiwavelength light produced by a cluster of semiconductor diodes and of each individual diode on mast cell number and degranulation in intact and injured skin. Lasers Surg Med., 10:559-568, 1990.

49. Dyson $\mathrm{M}$, and Young S: Effect of laser therapy on wound contraction and cellularity in mice. Lasers in Medical Science, 1:125 130, 1986.

50. Shiroto C, Sugawara K, Kumae T, O no Y, Sasaki M, and Ohshiro $\mathrm{T}$ : Effect of diode laser radiation in vitro on activity of human neutrophils. O riginal Articles, 135 140, 1990.

51. Abergel RP, Lyons RF, Castel JC, D wyer RM, and Uitto $\mathrm{J}$ : Biostimulation of wound healing by lasers: Experimental approaches in animal models and in fibroblast cultures. Journal of Dermatological and Surgical Oncology, 13:127-133, 1987. 
52. Young S, Bolton $\mathrm{P}$, Dyson M, Harvey W, and Diamantopoulos C: Macrophage responsiveness to light therapy. Lasers in Surgery and Medicine, 9:497 505, 1989.

53. Haas AF, Isseroff $R$, Wheeland $R G$, Rood PA, and Graves PJ: Low energy helium neon laser irradiation increases the motility of cultured human keratinocytes. The Journal of Investigative D ermatology, 94:822 826, 1990.

54. Abergel RP, Meeker CA, Lam TS, D wyer RM, Lesavoy MA, Uitto J. Control of connective tissue metabolism by lasers: recent developments and future prospects. J Am Acad D ermatol,11:1142-1150, 1984.

55. Graham DJ, Alexander JJ. The effects of argon laser on bovine aortic endothelial and smooth muscle cell proliferation and collagen production. Curr Surg, 47:27-30, 1990.

56. Pogrel MA, Chen JW, Zhang K. Effects of low-energy gallium-aluminum-arsenide laser irradiation on cultured fibroblasts and keratinocytes. Lasers Surg Med, 20:426432, 1997.

57. Steinlechner $C, D$ yson $M$. The effects of low level laser therapy on the proliferation of keratinocytes. Laser Therapy, 5:65-73, 1993.
58. Utsunomiya T: A histopathological study of the effects of low power laser irradiation on wound healing of exposed dental pulp tissues in dogs, with special reference to lectins and collagens. Journal of Endodontics, 24:187 193, 1998.

59. Lam TS, and Abergel RP: Laser stimulation of collagen synthesis in human skin fibroblast cultures. Lasers in the Life Sciences, 1:61 77, 1986.

60. Skinner SM, Gage JP, Wilce PA, and Shaw RM: A preliminary study of the effects of laser irradiation on collagen metabolism in cell culture. Australian Dental Journal, 41:188-192, 1996.

61. Lyons RF, Abergel RP, White RA, D wyer RM, Castel JC, Uitto J. Biostimulation of wound healing in vivo by a helium-neon laser. Ann Plast Surg, 18:47-50, 1987.

62. Saperia D, G lassberg E, Lyons RF, Abergel RP, Baneux P, Castel JC, D wyer RM, Uitto J. D emonstration of elevated type I and type III procollagen mRNA levels in cutaneous wounds treated with helium-neon laser. Proposed mechanism for enhanced wound healing. Biochem Biophys Res Commun, 138:1123-1128, 1986.

63. Welch AJ, Y oon G. van G emert MJC. Practical Models for Light Distribution in Laser- Irradiated Tissue. Lasers in Surgery and Medicine. 1987;6:488-93.

\section{Join the World}

\section{WALT \\ Join The World Association for Laser Therapy (WALT)}

How To Join

(1) Wire transfer your journal subscription and membership fee directly to Kansas Corporate Credit Union, Wichita, Kansas (routing number 301180111). To ensure proper credit, you must instruct Kansas Corporate Credit Union as follows: "Please further credit KUMC Credit Union (assound ABA: 301078731) for deposit in Walt '98 account number 30475".

\section{OR}

(2) Send a countersigned Traveler's Check or an international bank draft (made payable to WALT) to the Editor-in-Chief or the Business Manager (see address in this issue of the journal).

OR

(3) Pay by credit card at our Website: [www.walt.nu ]. 